Çukurova Üniversitesi Mühendislik Mimarlık Fakültesi Dergisi, 33(3), ss. 57-66, Eylül 2018

Çukurova University Journal of the Faculty of Engineering and Architecture, 33(3), pp. 57-66, September 2018

\title{
Patlatma Uygulaması Yapılan Bir Sahadan Elde Edilen Titreşim Değerlerinin Farklı Hasar Kriter Tablolarına Göre Değerlendirilmesi
}

\author{
Serdar ERCINS ${ }^{1}$, Cem ŞENSÖĞÜT*2 \\ ${ }^{1}$ Cumhuriyet Üniversitesi, Sivas MYO, Madencilik ve Maden Çıkarma Bölümü, Sivas \\ ${ }^{2}$ Dumlupinar Üniversitesi, Mühendislik Fakültesi, Maden Mühendisliği Bölümü̈, Kütahya
}

Geliş tarihi: 09.07.2018 Kabul tarihi: 03.09.2018

\begin{abstract}
Özet
Patlayıcı maddelerin gelişen teknolojilerle birlikte güncellenmesi ve birçok alanda kullanılabilir hale gelmesi, patlayıcı madde tüketimini artırmıştır. Patlayıcı maddelerin yanlış ve bilinçsiz kullanılması, patlatmalı kayaç kazılarının yapıldığı maden ve taş ocaklarında, endüstriyel yapılarda, her türlü inşaat faaliyetlerinde, yeraltı ve yerüstü yapılarında yapısal hasarlara ve canlılar üzerinde de psikolojik sorunlara yol açabilmektedir. Patlatma uygulamalarından kaynaklanan titreşim, hava şoku ve toz gibi problemlerin en aza indirilmesi için patlatma performans analizlerinin yapılması ve sahanın yapısına uygun patlatma tasarımlarının uygulanması gerekmektedir. $\mathrm{Bu}$ analiz ve tasarımların uygunluğu belirlenirken, birçok ülkenin oluşturmuş olduğu hasar kriter tablo ve grafiklerinden yararlanılmaktadır. Ülkemizde 2005 yılına kadar Amerikan (USBM, OSMRE) değerlendirme tablolarından yararlanılmış ve bu yıldan sonra "Çevre ve Orman Bakanlığı Çevresel Gürültünün Değerlendirilmesi ve Yönetimi Yönetmeliği’nde yer alan ve Amerikan normları ile neredeyse benzer olan "Türk Hasar Değerlendirme Kriterleri" yayımlanarak yürürlüğe girmiştir. Özellikle patlatmadan kaynaklanan titreşim etkilerinin çevrede bulunan yerleşim yerleri ile yapılar üzerinde hasar oluşturup oluşturmadığı, Türk hasar değerlendirme grafiğinde yer alan sınır eğrisi kabul edilerek belirlenmektedir. Ancak bazı durumlarda patlatma uygulamalarından elde edilen titreşim değerleri bu eğrinin altında kalsa dahi, yapılar üzerinde bazı hasarlar yaratabilmektedir. Bu çalışmada, nonel ateşleme sistemi ile yapılan patlatma uygulamalarından elde edilen titreşim değerlerinin, Türk ve Alman DIN4150 hasar değerlendirme kriterlerine göre hasar verme potansiyelleri irdelenmiştir. Sonuçta, patlatma uygulamalarından elde edilen tüm titreşim değerlerinin Türk hasar değerlendirme eğrisinin altında kaldığı ve herhangi bir hasar verme potansiyelinin olmadığı anlaşılmıştır. Ancak Alman DIN4150 normuna göre irdelendiğinde, birkaç parçacık hızının en altta bulunan ve kerpiç, eski yıpranmış tarihi eserler gibi sağlam olmayan yapılar için izin verilen en yüksek sınırı gösteren eğrinin üzerine çıktığı ve hasar verme potansiyelinde olduğu, birkaç parçacık hızının da eğriye neredeyse sınırda kaldığı görülmüştür.
\end{abstract}

Anahtar Kelimeler: Patlatma, Çevresel etkiler, Performans, Amerikan (USBM, OSMRE) hasar değerlendirme tablosu, Türk hasar değerlendirme kriterleri, Alman DIN4150 normu

*Sorumlu yazar (Corresponding author): Cem ŞENSÖĞÜT, sensogut@dpu.edu.tr 


\title{
Evaluation of Vibration Values Obtained from a Field Performed Blasting Application According to Different Damage Criterion Tables
}

\begin{abstract}
Updating explosive materials together with developing technologies and making many areas available increased the consumption of explosives. Incorrect and unconscious use of explosives in mines and quarries where explosive rock excavations are made, in industrial structures, in all kinds of construction activities may cause structural damage in underground and aboveground structures, and psychological problems in living beings. In order to minimize the problems such as vibration, air shock and dust caused by blasting applications, it is necessary to carry out blasting performance analyzes and apply appropriate blasting patterns to the field structure. While the appropriateness of these analyzes and designs is determined, damage criterion tables and graphs are used that are generated by many countries. Until 2005, USA (USBM, OSMRE) evaluation tables were utilized in Turkey and after this year, "Turkish Damage Assessment Criteria", which is similar to American norms, took place in the "Environmental Hazard Assessment and Management Regulation" of the Ministry of Environment and Forestry. Especially, whether the vibration effects caused by detonation damaging to surrounding settlements and constructions is determined by accepting the boundary curve in the Turkish damage assessment chart. In some cases, however, even if the vibration values obtained from the blasting applications remain below this curve, they can cause some damage to the constructions. In this study, damage potentials of blasting applications made with nonel ignition system are evaluated according to Turkish and German DIN 4150 damage assessment criteria.
\end{abstract}

As a result, it has been understood that all vibration values obtained from blasting applications are below the Turkish damage assessment curve and there is no potential for any damage. However, when considered according to the German DIN 4150 norm, a few particle velocities appeared to be at the bottom and potentially damaging to the curve showing the highest permissible limit for unstable constructions such as mudbrick, old worn historical artifacts.

Keywords: Blasting, Environmental effects, Performance, USA (USBM, OSMRE) evaluation damage table, Turkish damage evaluation criterions, German DIN4150 norm

\section{GíRiş}

Günümüzde patlayıcı kullanımının kaçınılmaz olduğu maden ve taş ocağı, baraj inşaatı, altyapı kazıları, tünel ve boru hattı çalışmaları gibi birçok sektörde, patlatmadan kaynaklanan titreşim, hava şoku ve toz oluşumu gibi çevresel sorunlar ile oldukça sık karşılaşılmaktadır. $\mathrm{Bu}$ sorunlar, çalışma bölgesi yakınında bulunan tüm canlılar ile yapıları doğrudan ve olumsuz yönde etkileyerek bazı psikolojik problemlerin de ortaya çımasına sebep olabilmektedir. Çevresel ve psikolojik problemlerin etki düzeylerinin belirlenebilmesi için patlatma uygulamalarından kaynaklanan titreşim ve hava şoku düzeylerinin ölçülerek sonuçlarının değerlendirilmesi gerekmektedir. Bunun için bazı ülkeler kendi hasar değerlendirme kriter tablolarını oluşturmuşlardır.

Patlatmalı kayaç kazılarında, patlatma uygulamalarından kaynaklanan sismik dalgaların, endüstriyel yapılar, çevre yerleşim yerleri, inşaatlar, yeraltı yapıları ile şevler üzerinde oluşturabileceği titreşim değerlerinin sorun teşkil etmeyecek seviyede değerlendirilebilmesi için çalışılan ülkede kabul gören hasar kriteri tablolarına göre izin verilen limit değerlerinin altında olması gerekmektedir. Bu sebeple, çevresel 
yapılar açısından kritik bir bölgeye sahip olan maden, taş ocağı, tünel ve metro inşaatları gibi yerlerde patlatmalı kazı çalışmaları yapılırken, kontrollü patlatma uygulamaları gerçekleştirilmelidir. Patlatma deliklerinin belirlenecek uygun delik gruplamaları ve seçilecek uygun gecikme aralıkları ile tasarımlandırılmaları şeklinde gerçekleştirilen kontrollü patlatmalardan kaynaklanan sismik dalgaların çevrede bulunan yerüstü ve yeraltı yapıları ile şevler üzerinde oluşturacağ 1 titreşim etkilerinin değerlendirilmesi, hem değerlendiren kişinin konu üzerindeki mesleki tecrübesi hem de ülkede kabul gören hasar değerlendirme kriter tablo ve grafikleriyle yakından ilgilidir [1].

Ülkemizde "hasar değerlendirme kriterleri" çalışması uzun yıllar yapılmadı̆̆ kadar, Amerikan (USBM, OSMRE) değerlendirme tabloları kabul görmüş ve kullanılmıştır. 2005 yılında, Amerikan standartları olarak da ifade edebileceğimiz bu standartlar hemen hemen aynı şekilde benimsenerek, Türk hasar değerlendirme kriterleri olarak ilan edilmiştir [2].

Amerikan (USBM, OSMRE) değerlendirme tablosundaki titreşim hızı değerleri $(4-10 \mathrm{~Hz}, 19$ $\mathrm{mm} / \mathrm{sn}$ ), betonarme ve sağlam yapıda olan Amerikan evleri referans alınarak belirlendiği için, özellikle Türkiye'deki maden sahalarının yakınlarında bulunan kırsal alanlardaki yerleşik yapılara (köy evlerine, ahırlara, vb.) hasar verme ihtimalleri oldukça yüksektir.

Alman DIN4150'ye göre 10 Hz'den düşük olan frekans değerleri için, izin verilen en yüksek titreşim değeri $3 \mathrm{~mm} / \mathrm{s}$ 'dir (koruma altında bulunan yapılar için). Bina ve benzeri yapılar için $10 \mathrm{~Hz}$ 'den daha düşük olan frekanslarda izin verilen en yüksek parçacık hızı $5 \mathrm{~mm} / \mathrm{s}$ olarak belirlenmiştir.

Bu çalışmanın amacı, bir taş ocağı sahasında nonel ateşleme sistemi ile yapılan patlatma uygulamalarından elde edilen titreşim değerleri ile "Türk hasar değerlendirme kriterine" ve daha güvenli ve bizdeki köy evleri ile benzer yapıda düşünülebilecek olan, tarihi yapılar kategorisinde bulunan, evlere hasar vermeyecek düzeyde ve limit değerleri düşük olan (4-10 Hz arasında $5 \mathrm{~mm} / \mathrm{s}$ )
“Alman DIN4150 standardına" göre olușturulan hasar değerlendirme grafiklerini karşılaştırmalı olarak sunmaktır.

\section{UYGULAMA SAHASININ YERI VE JEOLOJIKK YAPISI}

Sivas İli, Merkez İlçesi, Yap1 Mahallesi'nde bulunan saha (Şekil 1), hammadde ocağ1 olarak kullanılmaktadır. Temelleri 1938 yılında atılan Sivas Çimento Fabrikası, hem Sivas ilinde kurulan ilk fabrika hem de Cumhuriyet tarihinde devlet eliyle kurulan ilk fabrikadır. Fabrika, Türkiye'nin sanayileşme ve kalkınma hamlesinde bir dönüm noktası olma özelliği de taşımaktadır. İlk olarak 1992 yılında özelleştirilen fabrika, 2015 yılında Votorantim Çimento bünyesine geçmiştir. Fabrikada yıllık toplam üretim kapasitesi ortalama 1 milyon 600 bin ton civarındadır [3]. Sahada (Şekil 2) patlatma uygulamaları nonel ateşleme yöntemleri ile gerçekleştirilmiş ve gerekli ölçümler alınmıştır.



Şekil 1. Votorantim çimento ocağının lokasyonu

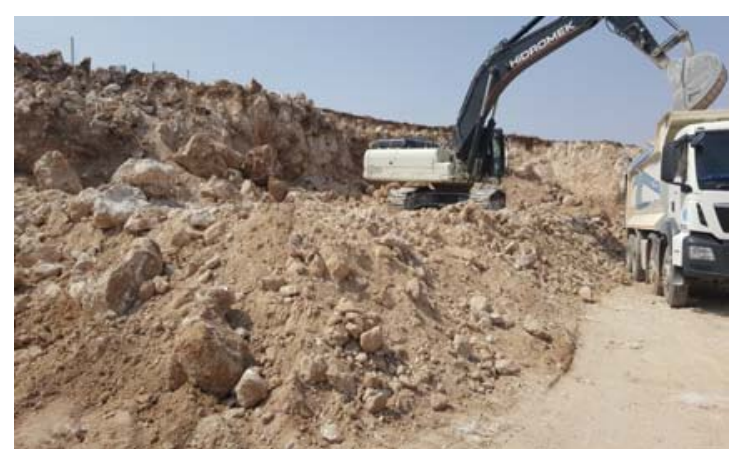

Şekil 2. Votorantim çimento ocağından bir görünüm 


\section{1. Ínceleme Alanı Jeolojisi}

A. Selimiye formasyonu: Sivas Tersiyer havzasında Oligosen yaşlı kırıntılı karasal oluşuklar, Selimiye formasyonu olarak adlandırılmıştır. Genel olarak morumsu, kırmızı yer yer alacalı gri renkte olan çakıl taş1, kumtaşı, silt taşı ve çamur taşı ardalanmasından oluşan birim, kaim, orta-kalın ve orta-ince katmanlıdır. Kırıntılı düzeylerde derecelenme ve çapraz katmanlar gibi sedimenter yapılar izlenmektedir [4].

B. Hafik formasyonu: Sivas havzasında oldukça geniş yayılım sunan ve ağırlıklı olarak masif jipslerden oluşan Oligo-Miyosen yaşlı birim Hafik formasyonu olarak adlandırılmıştır. Masif jipslere yer yer kırıntılı katmanlı jips ardalanmasından oluşan düzeyler de eşlik etmektedir. Dolin, ovala ve polye türü karstik yapıların yaygın olarak geliştiği bu birim, KB-GD ve KD-GB doğrultulu fayların ve kırık zonlarının denetiminde deformasyona uğramıştır. Karstik yapıların da kırık zonlarına bağlı olarak geliştiği kabul edilmektedir. Sivas dolayındaki yüzey ve yeraltı sularının büyük bir bölümü, bölgede çok geniş bir yayılım gösteren Hafik formasyonu jipslerinin etkisi sonucunda toplam çözünmüş iyon miktarı çok yüksek, tuzlu ve acı sulardır [4].

C. Kuvaterner Yaşlı Oluşuklar: İnceleme alanında ve yakın dolayında Kuvaterner yaşlı topraklar ve alüvyonlar ova konumunda olan düzlüklerde ve akarsu vadilerinde geniş bir alanda görülmektedir. Alüvyonlar genel olarak tutturulmamış ya da gevşek tutturulmuş ve taşınma evresi geçirmiş çakıl, kum ve çamur depolarıyla temsil edilmektedir. Topraklar ise ince taneli ve yerli yerinde oluşmuş ince taneli zeminleri temsil etmektedir. Ayrıca traverten ve yamaç molozu ya da alüvyon konileri yer yer izlenmektedir. Özellikle alüvyon ve Selimiye formasyonu üzerinde yerli yerinde oluşmuş toprak durumundadır. Kızılırmak vadisi boyunca ve Kızılırmak'a ulaşan vadilerde ya da yamaçlarda yer alan alüvyon ve toprak, yüzey sularının üzerinden aktığı düzeyleri oluşturmaktadırlar. $\mathrm{Bu}$ oluşukların, özellikle dolaylarındaki jipsli akiferlerden süzülen sulara yatak işlevini gören kesimleri, doğal olarak kirlenmiş, dolayısıyla içme ya da tarım amaçlı kullanımı sınırlı olan yer altı sularının sınırlı olarak bulunduğu akiferlerdir [4].

\section{YER TITREŞIMI VE HAVA ŞOKU IZLEME SISTEMLERİ}

Tipik bir örneği Şekil 1'de verilen yer titreşimi ve hava şoku izleme cihazı; enine, boyuna ve düşey algılayıcıları, mikrofon, şarj, yazıcı, bilgisayar bağlantı sistemi, kontrol ve hafiza, muhafaza ve taşıma birimlerinden oluşmaktadır. Sismograf (Instantel) cihazı üç boyutlu titreşimleri (PPV; $\mathrm{mm} / \mathrm{s}$ ) ölçebilmekte ayrıca bu cihaz 3 boyutlu hareketlerin vektörel toplamını da hesaplayabilmektedir. $\mathrm{Bu}$ hareketler ise, boyuna (Radial (R)), yanal (Transverse (T)) ve düşey (Vertical (V)) hareketlerdir. Ayrıca vektörel bileşke parçacık hızı (VS) ve en üst parçacık hızı (PPV) değerlerini de sismograf cihazı (Instantel) grafikte sunmaktadır. Bunun yanı sira, cihaz üzerinde bulunan dijital gösterge ile istenildiği zaman bu değerler görüntülenebilir ve kaydedilen veriler, üzerinde ayrıntılı analiz yapabilmek için bilgisayar ortamına aktarılabilmektedir.

Çalışmada kullanılan jeofonun frekansı $4 \mathrm{~Hz}$ olup, cihaz özellikleri Çizelge 1'de verilmiştir.

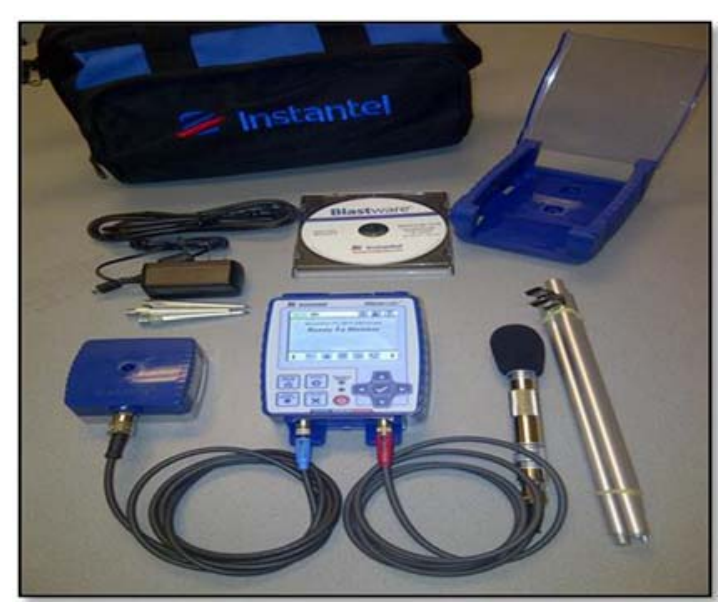

Şekil 3. Instantel Micromate titreşim ölçüm cihazı 
Çizelge 1. Instantel Micromate cihaz özellikleri

\begin{tabular}{|l|l|}
\hline Kanallar & $\begin{array}{l}\text { Mikrofon ve Üç Eksenli } \\
\text { Geophone (ISEE veya DIN) }\end{array}$ \\
\hline Mesafe & $\begin{array}{l}254 \mathrm{~mm} / \mathrm{sn} \text { 'ye kadar }(10 \\
\text { inç/s) }\end{array}$ \\
\hline Tepki standart & ISEE veya DIN 45669-1 \\
\hline Çözüm & $\begin{array}{l}0,00788 \mathrm{~mm} / \mathrm{s}(0,00031 \\
\text { inç/s) }\end{array}$ \\
\hline $\begin{array}{l}\text { Doğruluk } \\
\text { (ISEE/DIN) }\end{array}$ & $\begin{array}{l}+/-5 \% \text { veya } 0,5 \mathrm{~mm} / \mathrm{s}(0,02 \\
\text { inç/s), hangisi büyükse, } 4 \text { ila } \\
125 \mathrm{~Hz} / \mathrm{DIN} 45669-1 \\
\text { Standart }\end{array}$ \\
\hline $\begin{array}{l}\text { Dönüştürücü } \\
\text { Yoğunluğu }\end{array}$ & $2,0 \mathrm{~g} / \mathrm{cc}\left(127 \mathrm{lbs} / \mathrm{ft}^{3}\right)$ \\
\hline $\begin{array}{l}\text { Frekans Aralığ1 } \\
\text { (ISEE/DIN) }\end{array}$ & $\begin{array}{l}2-250 \mathrm{~Hz}, 0-(-3) \mathrm{dB} \text { arasında } \\
\text { ideal bir düz tepki/1 ila } 315 \\
\mathrm{~Hz}\end{array}$ \\
\hline $\begin{array}{l}\text { Maksimum Kablo } \\
\begin{array}{l}\text { Uzunluğu } \\
\text { (ISEE/DIN) }\end{array}\end{array}$ & $1000 \mathrm{~m}(3280 \mathrm{ft})$ \\
\hline
\end{tabular}

Cihaz, uygulamalarda anlık ya da sürekli kayıt yapabilmektedir. Her bir faaliyetin süresince (1-10 sn arasında uzaklığa bağlı olarak) 150-200 arasında uygulamayı geniş ya da özet bilgiler halinde kaydetme yeteneğine sahiptir. Cihazın ölçüm limitleri, gürültü için 100-148 dB, parçacık hızı için $0,127-253,9746 \mathrm{~mm} / \mathrm{sn}$ aralıkları düzeyindedir. $\mathrm{Bu}$ değerler içerisinde istenilen aralıklar dijital göstergeden ayarlanabilmektedir. Kullanıcıya ait bilgiler, kaydedilecek olay süresi, çalışma sahası, kayıt biçimi (tek ya da sürekli) ve istenilen birimler, önceden belirlenen şekilde programlanabilmektedir [5].

\section{YER TITREȘIMI KRITTERLERI}

Çeşitli araştırmacılar tarafından geliştirilen patlatma hasar kriterleri günümüze kadar değişik başarı dereceleriyle uygulanmıştır. $\mathrm{Bu}$ araştırmaların çerçevesi iki ana başlık altında ifade edilebilir.

1. Patlatma sonucu oluşan titreşim ve hava şokunun tanımlanması, ölçümü ve ilgili parametrelerin analizi.

2. Çeşitli yapılar için hasar kriterlerinin belirlenip, bu kriterlerin patlatma sonrasındaki parametrelerle eşleştirilerek uygun patlatma tasarımı.
Geliştirilen bu kriterler arasında, kullandıkları parametreler açısından benzerlik arz eden ve yaygin kabul görerek uygulamada başvuru ve mukayese kaynağı olarak kullanılan normlardan en önemli iki tanesi ABD Madencilik Bürosu'nun hasar kriteri, USBM RI8507 ve Alman DIN 4150 normudur [1].

Aşağıda Türk maden, inşaat ve taş ocakları için 2005 yılında kabul gören standarda ek olarak ABD Madencilik Bürosu'nun hasar kriteri USBM RI8507 ile Alman DIN 4150 normunun çizelgeleri verilmiş ve patlatma uygulamalarından elde edilmiş titreşim ölçüm sonuçları Türk ve Alman normlarına göre karşılaştırılmıştır.

\subsection{Amerikan Hasar Sınıflaması (USBM)}

Amerika Birleşik Devletleri Madencilik Dairesi'nin (USBM) ortaya koyduğu emniyetli titreşim seviyeleri ile hasar değerlendirme grafikleri Çizelge 2 ve Şekil 4'deki gibidir.

Çizelge 2. USBM'a göre emniyetli titreşim düzeyleri

\begin{tabular}{|l|c|c|}
\hline \multirow{2}{*}{ Yapı Türü } & \multicolumn{2}{|c|}{$\begin{array}{c}\text { En yüksek yer titreşim hız } \\
\text { değeri }\end{array}$} \\
\cline { 2 - 3 } & $\begin{array}{c}\text { Düşük frekans } \\
(<40 \mathrm{~Hz})\end{array}$ & $\begin{array}{c}\text { Yüksek frekans } \\
(>40 \mathrm{~Hz})\end{array}$ \\
\hline Modern Evler & 19,0 & 50,8 \\
\hline $\begin{array}{l}\text { Eski yapılar } \\
\text { (Ahşap Elemanl1) }\end{array}$ & 12,7 & 50,8 \\
\hline
\end{tabular}

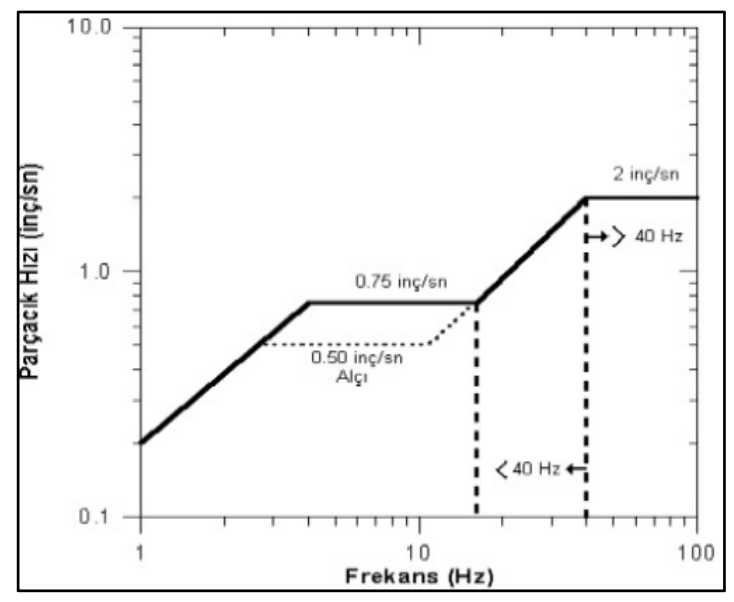

Şekil 4. USBM hasar değerlendirme grafiği 


\subsection{Türkiye Standardı}

Ülkemizde bu konu ile ilgili ilk yönetmelik (2002/49/EC) 01.08.2005 tarihi ile yürürlüğe girmiş ve 04.06.2010 tarihinde "Çevresel Gürültünün Değerlendirilmesi ve Yönetimi Yönetmeliği” başlığı değiştirilerek en son halini almıştır. Bu standarda göre izin verilen en yüksek değerler Çizelge 3'de, sınır grafiği ise Şekil 5'de verilmiştir.

Çizelge 3. Maden ve taş ocakları ile benzeri alanlarda patlama nedeniyle oluşacak titreşimlerin en yakın çok hassas (Ek ibare: RG-27/4/2011-27917) ve hassas kullanım alanının dışında yaratacağı zemin titreșimlerinin izin verilen en yüksek değerleri [6]

\begin{tabular}{|c|c|}
\hline $\begin{array}{c}\text { Titreşim Frekans1 } \\
(\mathrm{Hz})\end{array}$ & $\begin{array}{c}\text { İzin Verilen En Yüksek Titreşim } \\
\text { Hızı (Tepe Değeri-mm/s) }\end{array}$ \\
\hline 1 & 5 \\
\hline $4-10$ & 19 \\
\hline $30-100$ & 50 \\
\hline
\end{tabular}



Şekil 5. Türkiye'de geçerli yönetmelikteki sınır değerlere göre çizilmiş grafik

\subsection{Alman DIN4150 Hasar Kriteri}

Alman DIN 4150 Standard1, tüm hasar kriterlerinde, frekans, parçacık hızı ve yapı türlerini esas alan ve aynı zamanda en güvenilir olan normlardan birisidir $[7,8]$.
Alman standardına göre yapı tipi ile hız-frekans ilişkisi Çizelge 4'de verilmektedir. Bu norm, grafiksel olarak incelendiğinde, en altta bulunan çizgi kerpiç, eski, yıpranmış tarihi eserler gibi sağlam durumda olmayan yapılar, ortada bulunan çizgi yığma tuğla, beton gibi oldukça dayanıklı yapılar, üstteki çizgi ise betonarme çelik yapı gibi dayanıklı yapılar için titreşim frekansına göre parçacık hızı sınırlarını belirlemektedir (Şekil 6) [9].

Çizelge 4. Alman standartlarına göre (DIN4150) yapı tipi, hı-frekans iliskisi [10]

\begin{tabular}{|c|c|c|c|c|c|}
\hline \multirow{2}{*}{\multicolumn{2}{|c|}{ Yapı Tipi }} & \multicolumn{3}{|c|}{$\begin{array}{l}\text { Binaların Temelinde En Büyük } \\
\text { Titreşim Hızı, } \mathrm{mm} / \mathrm{sn} \\
\text { (frekansa göre, } \mathrm{f}=\mathrm{Hz} \text { ) }\end{array}$} & \multirow{2}{*}{$\begin{array}{c}\text { Tüm } \\
\text { frekanslar } \\
\text { için en } \\
\text { üst katın } \\
\text { tabanında } \\
* *\end{array}$} \\
\hline & & $f=1-10$ & $f=10_{-50}$ & $f=50-100 *$ & \\
\hline 1 & $\begin{array}{l}\text { Büro ve } \\
\text { endüstri } \\
\text { binaları }\end{array}$ & 20 & $20-40$ & $40-50$ & 40 \\
\hline 2 & $\begin{array}{l}\text { Oturulan } \\
\text { evler, sivalı } \\
\text { yapilar }\end{array}$ & 5 & $5-15$ & $15-20$ & 15 \\
\hline 3 & $\begin{array}{l}\text { Titreşime } \\
\text { duyarlılıkları } \\
\text { nedeniyle } 1 . \\
\text { ve } 2 \text {. } \\
\text { maddenin } \\
\text { dişında kalan } \\
\text { binalar }\end{array}$ & 3 & $3-8$ & $8-10$ & 8 \\
\hline \multicolumn{6}{|c|}{$\begin{array}{l}\text { * } 100 \text { devir/sn büyük frekanslar için, büyük titreşim } \\
\text { seviyesine izin verilebilir. } \\
\text { ** Birden fazla katlı binalar için, ölçümlerin hem binaların } \\
\text { temelinde hem de en üst katın tabanında alınması gerekir }\end{array}$} \\
\hline
\end{tabular}

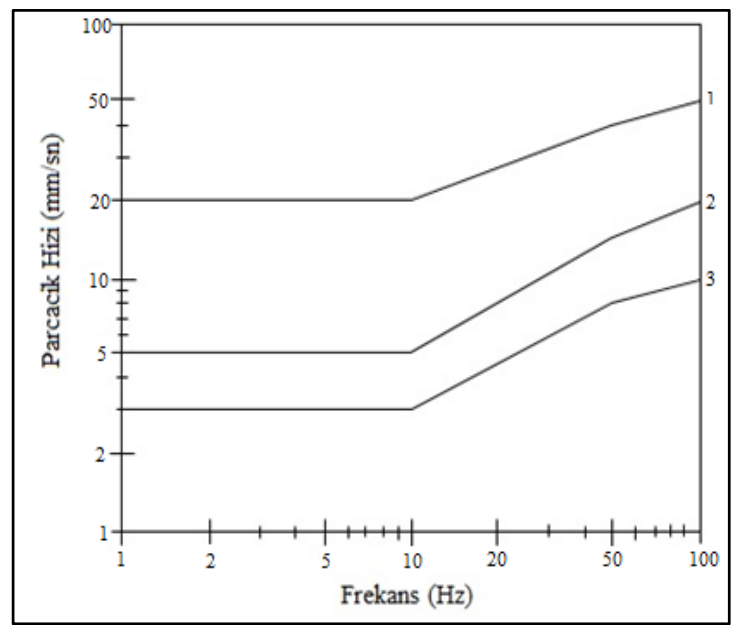

Şekil 6. Alman DIN 4150 normu kriter analizi [10] 
Alman DIN 4150 normu, diğer hasar sinıflandırmalarına göre daha korumacidır. Örneğin 1-10 Hz gibi frekansların ortaya çıktığı açık ocak patlatmalarında, yerleşim yerlerinde bulunan betonarme yapılar için $5 \mathrm{~mm} / \mathrm{s}$ parçacık hızındaki titreşimin aşılmamasını ister. Oysaki Amerikan USBM hasar standardı ve bu standarttan esinlenerek hazırlanmış olan "T.C. Çevre ve Şehircilik Bakanlığı” yönetmeliğine göre, aynı frekanslarda izin verilen sınır değer $19 \mathrm{~mm} / \mathrm{s}$ gibi çok yüksek bir değerdir. Bu değer, maden ve taş ocaklarının etrafinda bulunan yerleşik köy evleri ile betonarme olmayan yapılar için tahrip edici bir değerdir. $\mathrm{Bu}$ nedenle, patlatmadan kaynaklanan titreşim analizi yapılırken diğerlerine göre daha güvenli tarafta bulunan Alman DIN 4150 hasar sınır değerlerinin de dikkate alınması oldukça önem teşkil etmektedir [1]

\section{SAHADA YAPILAN NONEL ATESLEME UYGULAMALARI}

Çimento üretimi yapılan kalker sahasında nonel ateşlemeyle yapılan patlatma uygulamalarına (Şekil 7, 8) dair veriler Çizelge 5'de, sunulduğu gibidir.

\section{Çizelge 5. Kayaç ve patern bilgileri}

\begin{tabular}{|c|c|c|c|c|c|c|c|c|c|}
\hline $\begin{array}{l}0 \\
z \\
\dot{E} \\
\text { D. }\end{array}$ & 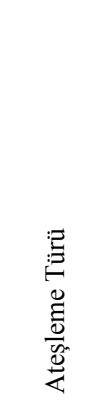 & 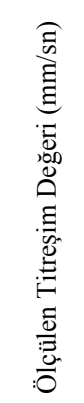 & 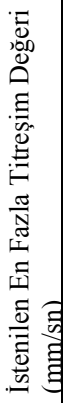 & 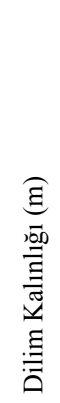 & 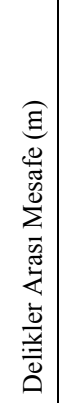 & 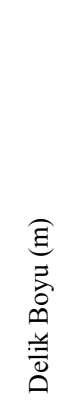 & 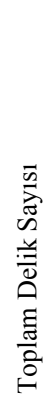 & 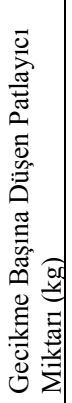 & 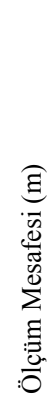 \\
\hline 1 & Nonel & 3,476 & 5 & 2,5 & 2,5 & 10,5 & 85 & 37 & 274 \\
\hline 2 & Nonel & 2,049 & 5 & 2,5 & 3 & 10,5 & 85 & 40 & 302 \\
\hline 3 & Nonel & 2,782 & 5 & 2 & 3 & 10,5 & 87 & 39 & 252 \\
\hline 4 & Nonel & 4,619 & 5 & 2,5 & 3 & 10,5 & 83 & 41 & 247 \\
\hline 5 & Nonel & 2,735 & 5 & 3 & 3 & 10,5 & 85 & 36 & 264 \\
\hline 6 & Nonel & 4,674 & 5 & 2,5 & 2,8 & 10,5 & 85 & 40 & 221 \\
\hline 7 & Nonel & 2,861 & 5 & 2,5 & 2,5 & 10,5 & 85 & 38 & 280 \\
\hline
\end{tabular}

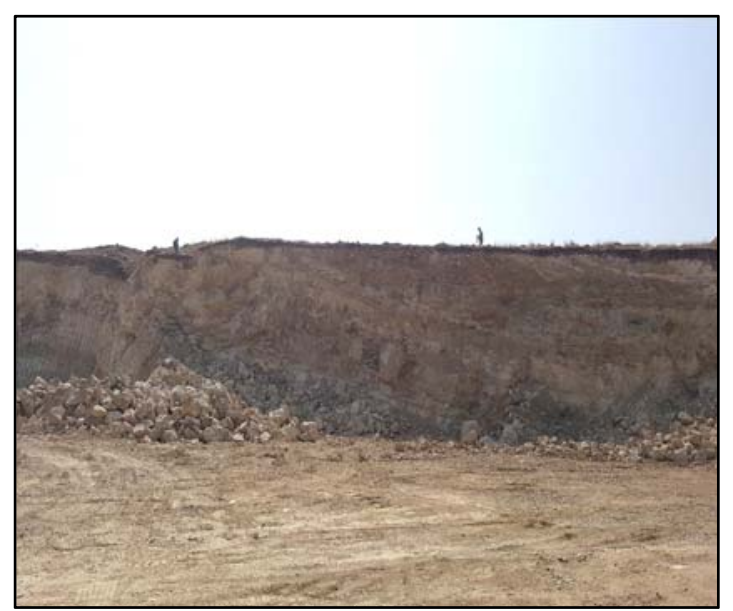

Şekil 7. Votorantim çimento ocağında patlatma öncesi bir görünüm

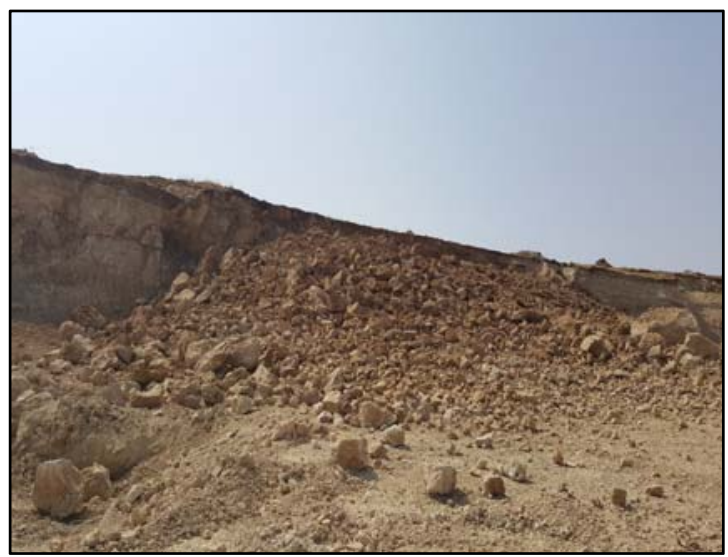

Şekil 8. Votorantim çimento ocağında patlatma sonrası bir görünüm

Şekil 8'de, işletmenin Çizelge 5'de verilen değerler ile kendi patlatma tasarımına göre yapmış olduğu patlatma uygulamalarından oluşan titreşimlerin, sahaya en yakın mesafede ve hasar alma ihtimalleri yüksek olan taşınmazlar ile askeriyeye ait olan alanların bulunduğu sınır bölgelerde ölçümü alınan titreşimlere ait parçacık hızlarının Türk hasar değerlendirme grafiğgine göre durumu görülmektedir.

Şekil 8 incelendiğinde belirlenen ölçüm noktalarında alınan titreşim değerlerinin Yanal (Tran), Düşey (Vert) ve Boyuna (Long) kaydedilen parçacık hızlarının tamamının sınır değerler 
dâhilinde belirlenmiş olan eğrinin altında kaldığı görülmektedir. Diğer bir ifade ile işletmenin gerçekleştirmiş olduğu patlatma uygulamalarının, ölçüm mesafeleri dâhilinde bulunan bölgelere hasar verme potansiyeli bulunmamaktadır.

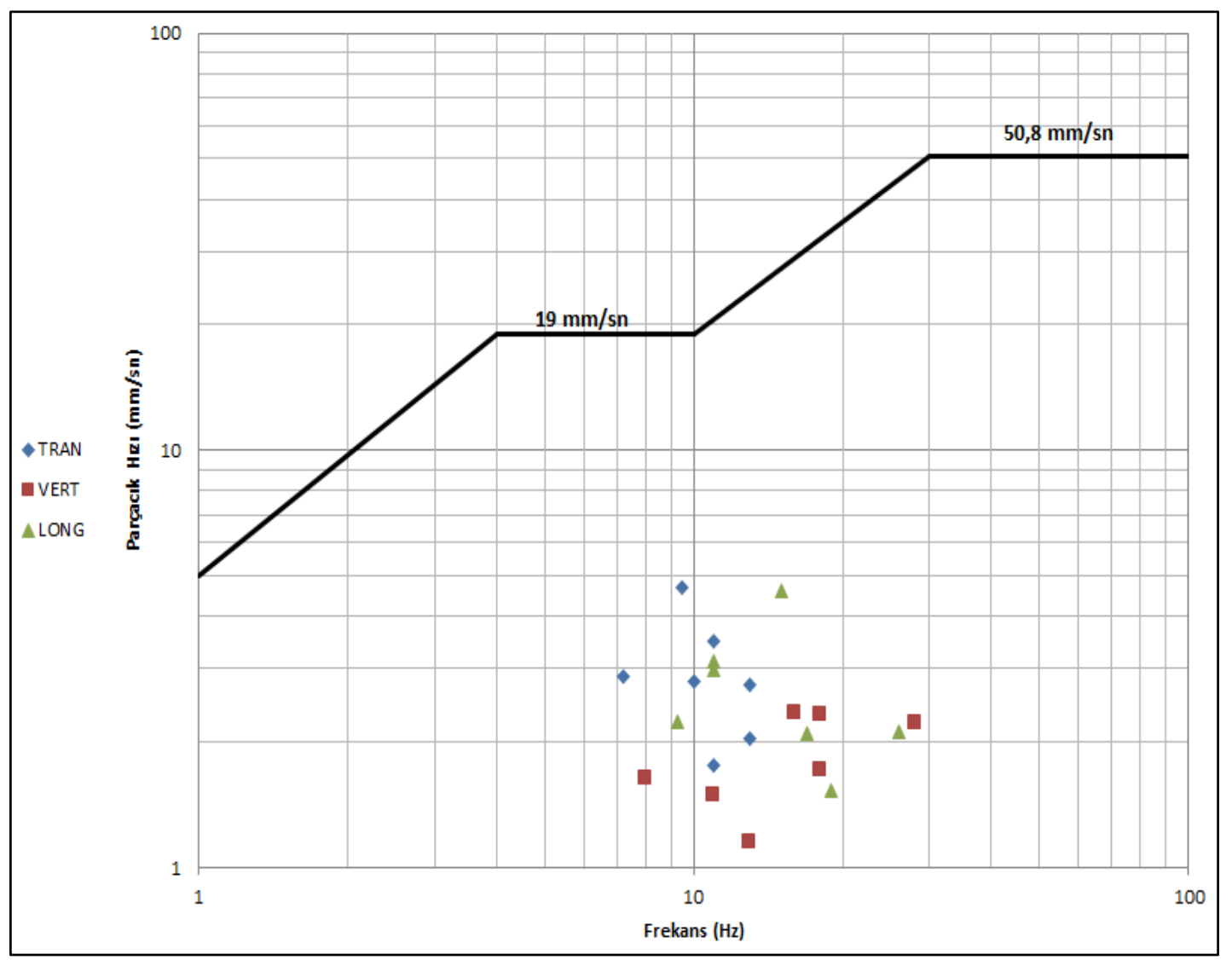

Şekil 9. Türk hasar değerlendirme grafiğine göre titreşim verilerinin durumu

Şekil 9'da ise Çizelge 5'de verilen delik patern değerleri ile işletmenin kendi patlatma tasarımına göre yapmış olduğu patlatma uygulamalarından oluşan ve belirlenmiş ölçüm mesafelerine göre elde edilen titreşimlere ait parçacık hızlarının Alman DIN4150 normuna göre durumu görülmektedir.

Maden ve taş ocaklarının bulunduğu bölgelerde, daha çok kırsal alanlarda kalan ve tarihi yapı niteliği taşıyan yapıların ve özel bölgelere (askeri bölge, şahsa ait tarla, vb.) sınır olan alanların, patlatma uygulamalarından ne düzeyde etkilendikleri Alman DIN4150 hasar değerlendirme normuna göre değerlendirilir ve
Şekil 9 incelenirse, belirlenen ölçüm noktalarında alınan titreşim değerlerinin bazılarının Yanal, Düşey ve Boyuna kaydedilen parçacık hızlarının, en altta bulunan ve kerpiç, eski yıpranmış tarihi eserler gibi sağlam olmayan yapılar için izin verilen ve maksimum sınırı gösteren eğrinin üzerine çıktığı ve hasar verme potansiyeline sahip titreşimler olduğu şeklinde yorum yapılabilir.

Şekil 10 üzerinden yapılacak olan bir diğer değerlendirme de, patlatma uygulamalarının herhangi bir hasar ve zarar oluşturma olasıllğına karşın patlatma dizaynının ve patern değerlerinin yeniden gözden geçirilmesi gerekmektedir denilebilir. 


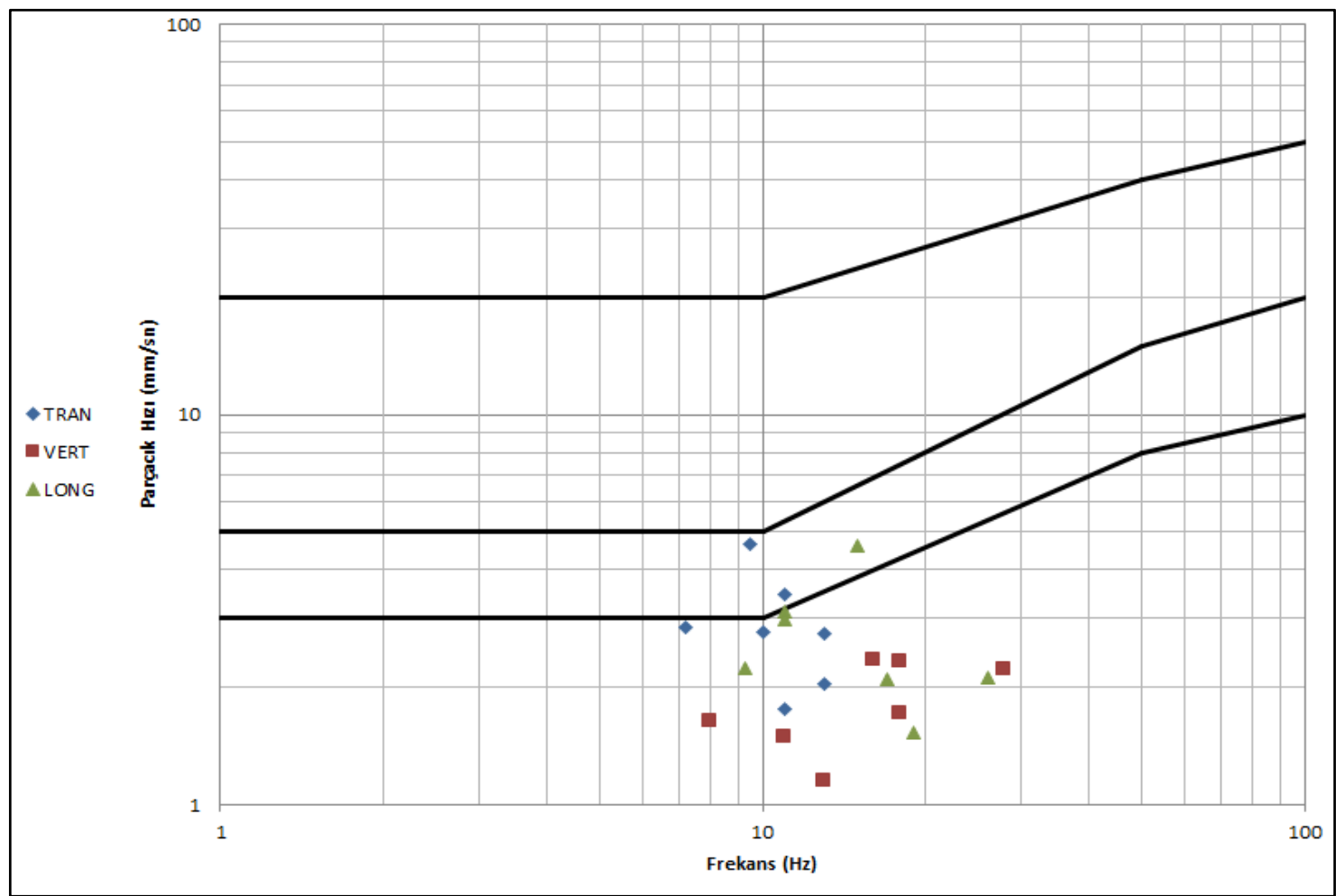

Şekil 10. Alman DIN4150 hasar normu grafiğgine göre titreşim verilerinin durumu

\section{SONUÇ VE ÖNERİLER}

Patlatma uygulamalarının nonel ateşleme sistemi ile gerçekleştirildiği sahada 7 adet titreşim ölçümü alınmıştır. Elde edilen sonuçlar hem "Türk hasar değerlendirme kriteri"ne göre hem de "Alman DIN4150 hasar normu"na göre irdelenmiştir. Saha ve civarında yaşanabilecek gerek yapısal gerekse psikolojik sorunlar değerlendirildiğinde, elde edilen titreşim verilerinin tümünün Türk hasar değerlendirme eğrisinin altında kaldığı, yani parçacık hızlarının en yüksek sınır değeri olan $19 \mathrm{~mm} / \mathrm{sn}^{\prime} \mathrm{yi}$ aşmadiğı ve hasar verme potansiyelinin olmadığı görülmüştür. Ancak aynı titreşim verileri Alman DIN4150 normuna göre irdelendiğinde, birkaç parçacık hızının en altta bulunan ve kerpiç, eski yıpranmış tarihi eserler gibi sağlam olmayan yapılar için izin verilen en yüksek sınırı gösteren eğrinin üzerine çıktığı ve hasar verme potansiyelinde olduğu, birkaç parçacık hızının da eğriye neredeyse sınırda kaldığı görülmüştür.
Patlatma uygulamalarının yapıldığı açık işletme sahalarında, hem yapısal hem de psikolojik anlamda yaşanabilecek olumsuzlukların incelenmesine yönelik çalışmalar yapılırken, özellikle maden ve taş ocaklarında gerçekleştirilen patlatmaların yaklaşık 4-10 $\mathrm{Hz}$ civarında etken frekanslı dalga ürettiği düşünüldüğünde, Türk standartlarına göre izin verilen parçacık hızı değerinin $(19 \mathrm{~mm} / \mathrm{s})$, ülkemizde kırsal alanlarda bulunan yapılara göre yüksek olduğu unutulmamalıdır. Özellikle kendi yapılarımıza uygun standartların oluşturulmasına yönelik çalışmalar başlatılmalı ve kendi standartlarımız oluşana kadar maden ve taş ocaklarında patlatma uygulamalarından kaynaklanan olumsuzluklar her üç hasar değerlendirme normuna göre incelenmelidir.

Ateşleme sistemleri ile patlatma uygulamalarından kaynaklanan çevresel ve psikolojik etkilerin yok edilmesi ya da etkilerinin en aza indirilmesi için özellikle maden ve taş ocaklarında yapılan 
patlatmaların performanslarını analiz edebilmeye yönelik değerlendirme modelleri incelenmeli ve alınan ölçüm sonuçları sürekli karşılaştırılmalıdır.

Ayrıca kontrollü patlatma uygulamalarının ve sahanın jeolojik yapısına uygun patlatma tasarımlarının belirlenip, süreç iyileştirme çalışmaları ile geliştirilmesi oldukça önem arz etmektedir.

\section{KAYNAKLAR}

1. Uyar, G.G., 2017. Patlatma Kaynaklı Titreşimlerin Çevreye Olan Etkilerinin En Aza İndirilmesi Çalışmalarında Kullanılan Hasar Kriter Tabloları Üzerine Bir Yorum, Uluslararası Madencilik ve Çevre Sempozyumu, Muğla/Türkiye.

2. Çevre ve Orman Bakanlığı Çevresel Gürültünün Değerlendirilmesi ve Yönetimi Yönetmeliği, 01.07.2005 Tarihli ve 25862 Sayılı Resmi Gazete.

3. https://www.dunya.com/sirketler/brezilyalicimento-devi-votorantimden-sivasa-140milyon-euroluk-yatirim-haberi-371165

4. Votorantim Çimento Sanayi ve Tic. A.Ş. Sivas 2013. Çimento Fabrikası ve Malzeme Ocakları Hidrojeolojik Etüt Raporu Sivas İli, Merkez İlçesi, Yapı Mahallesi Mevkii Yasin Doğan Müh. Mad. İnş. Tur. San. ve Tic. Ltd. Şti. Sivas.

5. Bağdatlı, S., 2013. Üsküdar-ÜmraniyeÇekmeköy Metro Hattı Libadiye İstasyonu Yaklaşım Tüneli Kazısında Yapılan Patlatmalı Kazılardan Kaynaklanan Titreşimlerin Ölçülmesi ve Çevresel Etkilerinin Değerlendirilmesi, Yüksek Lisans Tezi, Okan Üniversitesi, Fen Bilimleri Enstitüsü, İstanbul.

6. Anon, 2010. Çevresel Gürültünün Değerlendirilmesi ve Yönetimi Yönetmeliği, T.C. Çevre ve Orman Bakanlığı, Ankara.

7. Kahriman, A., Karadoğan, A.K., Görgün, S., Tuncer G., 1999. Taş Ocaklarında Patlatmadan Kaynaklanan Yer Sarsıntısının Ölçülmesi ve Analizi 2. Ulusal Kırmataş Sempozyumu 99, İstanbul, 129-141.

8. Atlas Powder Company, 1987. Explosives and Rock Blasting, Filed Technical Operations,
Subsidiary of the Tyler Corporation, Dallas, Texas, USA.

9. Akçakoca, H., Uysal, Ö., 2011. Bursa İli Osmangazi İlçesi, Kireçlik Tepe Mevkii, Tekinyol Kırmataş Ocağında Yapılan DelmePatlatmaların Çevresel Etkilerinin Değerlendirilmesi, Dumlupınar Üniversitesi Maden Mühendisliği Bölümü, Kütahya.

10. Schillinger, R., 2006. The State of Human Annoyance at Blasting Works in Accordance with Environmental Conditions Under Inclusion of Standards, Proceedingsof The Thirty-Second Annual Conference on Explosives and BlastingTechnique, 29 January-1 February, USA, 135-148. 